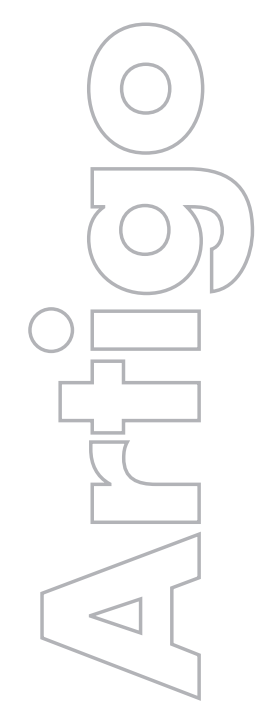

revista

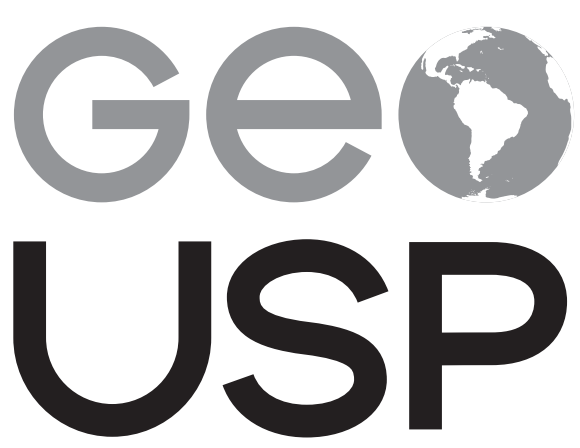

espaço e tempo

Volume $21 \cdot n^{\circ} 3(2017)$

ISSN 2179-0892
Necropolíticas espaciais

e juventude masculina: a relação entre a violência homicida e a vitimização de jovens negros pobres do sexo masculino

\author{
Fernando Bertani Gomes \\ Joseli Maria Silva
}

p. $703-717$

Como citar este artigo:

GOMES, F. B.; SILVA, J. M. Necropolíticas espaciais e juventude masculina: a relação entre a violência homicida e a vitimização de jovens negros pobres do sexo masculino. Geousp - Espaço e Tempo (Online), v. 21, n. 3, p. 703-717, dez. 2017. ISSN 2179-0892.

Disponível em: <http://www.revistas.usp.br/geousp/ article/view/127748> . doi: 10.11606/issn.2179-0892. geousp.2017.127748.

\section{(c) $)$ (i) (3)}

Este artigo está licenciado sob a Creative Commons Attribution 4.0 License. 


\title{
Necropolíticas espaciais e juventude masculina: a relação entre a violência homicida e a vitimização de jovens negros pobres do sexo masculino ${ }^{1}$
}

\section{Resumo}

Este artigo tem o objetivo de compreender a violência homicida como constituidora das periferias pobres vivenciadas por jovens homens. Para tanto, a ideia de periferia pobre é compreendida aqui como um espaço relacional e multiescalar (Massey, 2008) que envolve práticas de masculinidades específicas mediadas pelo biopoder (Foucault, 2006) e pela necropolítica (Mbembe, 2011). Foram analisados 86 inquéritos policiais de homicídios ocorridos entre 2012 e 2015 da 13a Subdivisão Policial de Ponta Grossa e das Varas Criminais da mesma cidade. O perfil mais vitimado encontrado na análise documental foi de pessoas do sexo masculino com idade entre 15 e 25 anos, moradoras de áreas periféricas pobres da cidade. $O$ perfil da violência homicida é originado de mecanismos e estratégias sociais de gestão da vida que fazem das periferias pobres e de seus jovens homens moradores a materialização da produção da morte.

Palavras-chave: Violência homicida. Jovens homens. Biopolítica. Necropolítica.

\section{Spatial necropolitics and masculine youth: the relationship between homicidal violence and the victimization of poor young black men}

\begin{abstract}
This article aims understand the homicide violence as constituent element of area poor which is experienced by young men. Therefore, the outskirts idea is understood in this research as a multi-scalar, relational space (Massey, 2008) involving specific practices masculinities assembled by biopower (Foucault, 2006) and the necropolitic (Mbembe, 2011). 86 police investigations about homicide occurred between 2012 and 2015 year were analyzed at the 13a
\end{abstract}

1 Presente artigo contou com as contribuições do Prof. Dr. Jan Simon Hutta, da Universidade de Bayreuth. Pelas trocas feitas a partir de leituras e debates, não poderíamos deixar de registar nosso agradecimento. 
Subdivisão Policial from Ponta Grossa. The most victimized profile say about young men with 15 until 25 years old, whom lived in area poor from city. The homicide violence profile is resulting of strategies and social mechanism of life management which doing on outskirts and its young men the materialization of the death production.

Keywords: Homicide violence. Young men. Biopolitic. Necropolitic.

\section{Introdução}

Este artigo tem por objetivo compreender a violência homicida como constituidora das periferias pobres, vivenciadas por jovens homens. Em 2011, a América Latina se destacou em número de homicídios, perdendo apenas para o Caribe, e o Brasil é o terceiro país com maiores índices de morte violenta, conforme Ingram e Costa (2014). O Instituto de Pesquisa Econômica Aplicada (Ipea, 2016) afirmou que o Brasil é o país campeão em números absolutos de mortes por assassinato no planeta.

A violência homicida é um fenômeno vivenciado de forma heterogênea espacial e temporalmente pelos variados grupos sociais. Há um perfil de vitimização ${ }^{2}$ já elaborado por Waiselfisz (2014) que evidencia haver uma diferenciação social, a partir de elementos concretos como a vitimização de jovens, do sexo masculino e negros. Waiselfisz (2012) alerta que os homicídios na faixa jovem tiveram uma taxa de 150,2\% superior ao restante da população. As vítimas, majoritariamente do sexo masculino, representaram em 2010, 91,4\% do universo considerado (Waiselfisz, 2013). Além disso, em 2001 morreram proporcionalmente 69,4\% mais negros do que brancos e em 2011 esse índice subiu para 136,8\% (Waiselfisz, 2014). A vitimação negra fica ainda mais acentuada se interseccionada com a faixa jovem. Para cada jovem branco, morrem 2,5 jovens negros.

A vitimização dos jovens envolvidos na violência homicida no Brasil apresenta uma espacialidade específica, sendo as periferias urbanas pobres os locais de maior incidência como pode ser visto pelos estudos de Alves (2013), Vargas (2010) e Reis (2005). O contexto espacial urbano desses autores são grandes cidades como São Paulo, Rio de Janeiro e Salvador, respectivamente. Mas, segundo Waiselfisz (2014), há um novo padrão emergente do fenômeno da violência no Brasil que é o declínio de índices de homicídios na última década em áreas metropolitanas e uma interiorização acentuada da violência rumo às áreas interioranas. Assim, o referencial empírico de análise para cumprir o objetivo deste artigo é a área urbana de Ponta Grossa, Paraná, um município considerado de porte médio no que diz respeito ao seu tamanho populacional ${ }^{3}$ e que está fora da região metropolitana da capital paranaense, Curitiba. O Gráfico 1 evidencia a tendência de crescimento:

2 O termo "vitimização" se distingue de "vitimação": este trata de corpos mortos e aquele se amplia para condições de vulnerabilidade.

3 Segundo o Censo 2010 (IBGE, 2011), o município de Ponta Grossa tem 311.611 habitantes, com uma população urbana de 304.733 pessoas, e fica a aproximadamente $100 \mathrm{~km}$ da capital. 


\section{Gráfico 1 - Taxa de homicídio em Ponta Grossa, Paraná e Brasil entre 2010-20154}

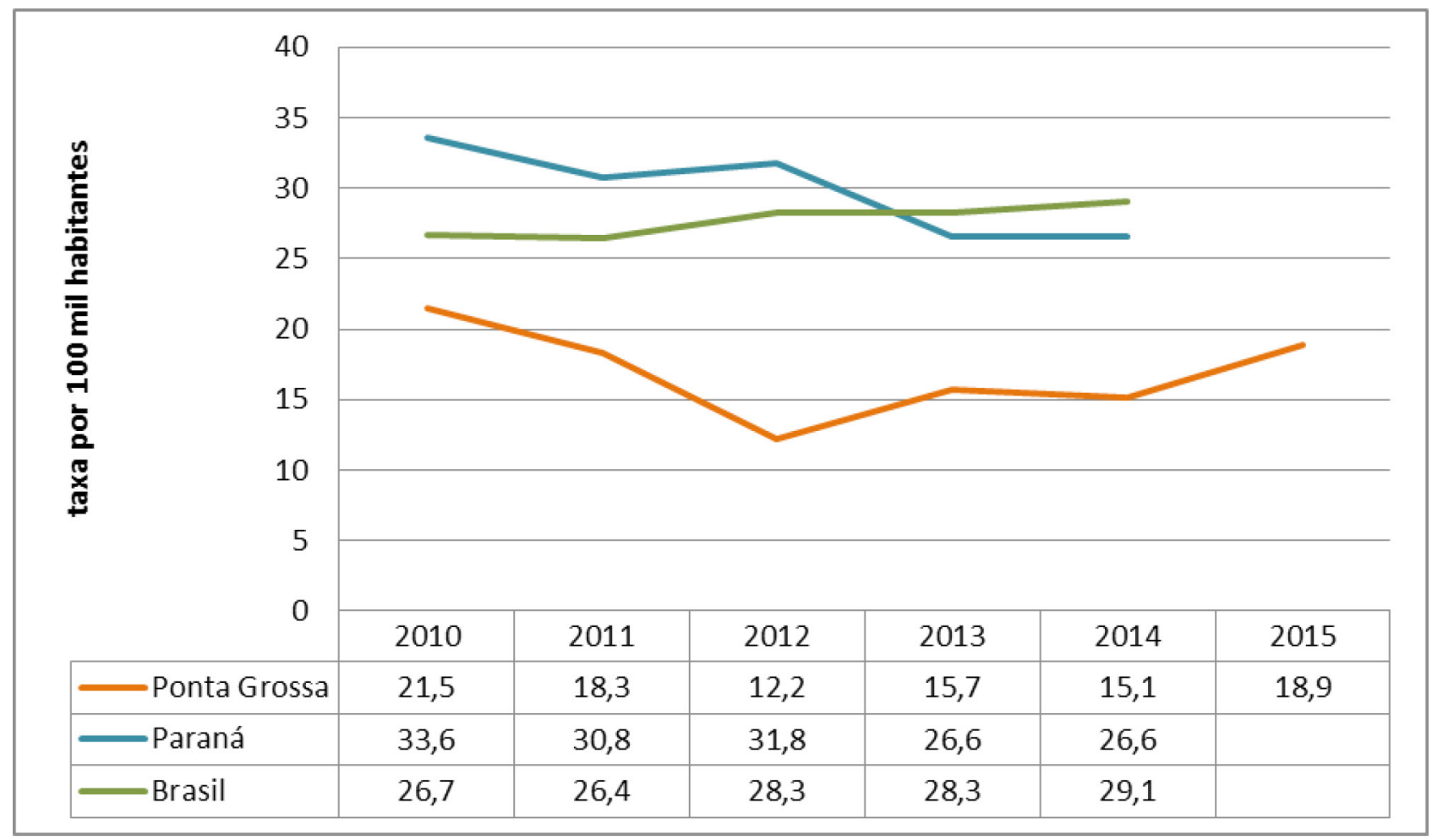

fonte: Ipea (2016); Paraná ([s.d.]).

Para embasar a análise, foram analisados 86 inquéritos policiais ${ }^{5}$ registrados entre os anos 2012 e $2015^{6}$ e ocorridos nos limites do município de Ponta Grossa. ${ }^{7} \bigcirc$ recorte temporal foi definido a partir de 2012, pelo fato dessa pesquisa ser um desdobramento da dissertação, em Gomes (2013) foram analisados os casos de homicídio entre 2010 e 2011, e foi delimitado até 2015 por ser o último a ser possível analisar a série anual.

Na primeira seção do artigo foi estabelecida uma discussão que considera a periferia pobre um lugar, no sentido proposto por Doreen Massey (2008). A periferia é um lugar constituído de relações sociais que se encontram e se entrelaçam em um lócus específico, se faz do encontro de momentos articulados em redes de relações, integrando ligações de outras escalas e constituindo o que a autora chama de um "sentido global do lugar". Esse sentido se faz de relações concretas cotidianas que incorporam o econômico, o político e o cultural na constituição do fenômeno da violência homicida que marca a trajetória dos jovens homens moradores das periferias brasileiras. A ideia de periferia como lugar privilegiado socialmente como produtor de mortes violentas, está vinculada com o fato de que algumas vidas são consideradas descartáveis e os processos que criam esta dinâmica espacial podem ser compreendidos pela biopolítica (Foucault, 2006) e necropolítica (Mbembe, 2003, 2011). Na segunda seção, são ex-

4 Não foram encontrados dados do Paraná e do Brasil para 2015, bem como de Ponta Grossa antes de 2010.

$5 \bigcirc$ acesso aos documentos foi autorizado pela delegada-chefe da 13a Subdivisão da Polícia Civil e pelos juízes de direito de cada uma das três Varas Estaduais Criminais no Fórum Municipal.

6 No recorte temporal, ocorreram 193 homicídios registrados no município.

7 A análise dos inquéritos foi facilitada por meio de um banco de dados em base LibreOffice, organizado conforme a disposição do documento e possibilitando o levantamento e o tratamento dos dados. 
plorados os dados que evidenciam a geograficidade do fenômeno, fazendo da periferia de Ponta Grossa uma cidade interiorana e majoritariamente branca ${ }^{8}$ do Paraná, um lugar do encontro multiescalar específico de dispositivos produtores de cadáveres.

\section{Espaço relacional e violência homicida como mecanismos da necropolítica}

O conceito de "necropolítica espacial" foi concebido por Alves (2011, 2013), baseado em Mbembe (2003), para construir a inteligibilidade da relação entre espaço, violência e racialidade, tomando a cidade de São Paulo como referencial de análise. $\bigcirc$ autor entende a raça uma representação social utilizada como um dispositivo social de poder construído para hierarquizar seres humanos. Esse dispositivo é definidor da lógica espacial de quem tem o direito de viver ou morrer, seja pela violência letal ou ainda pela negligência e cumplicidade do Estado com as várias faces da violência como a negação aos direitos de cidadania e a segregação espacial.

Para Alves $(2011,2013)$ a distribuição desigual da morte está calcada em uma necropolítica estatal de gestão do espaço urbano, entendendo que há uma simbiose entre espaço e raça na produção de territórios da violência. Sua base teórica geográfica trata o espaço pela perspectiva de Henri Lefebvre (1991) e Milton Santos (2007). Essa concepção espacial, característica pela simbiose espaço-raça, como proposto por Alves (2011, 2013), está imbuída da ideia de totalidade, na qual cada parte da cidade contém e expressa a própria totalidade, havendo uma conectividade instantânea, uma busca de uma singularidade universal e, portanto de uma sincronia. As periferias urbanas pobres e negras, concentradoras das estatísticas da violência homicida aparecem simultaneamente como produto da necropolítica e da condição para a perpetuação do controle dos grupos sociais marginalizados.

O geógrafo Nigel Thrift (2006) argumenta a necessidade de pensar o fenômeno da violência urbana superando a ideia de dualidade do espaço, como produto e condição de reprodução social, econômica e política e também a urgência de que a violência possa ser entendida para além de se constituir um reflexo das falhas estruturais. A violência não é unívoca, mas assenta-se nas práticas discursivas e estas são elaboradas na experiência espacial. Žižek (2009) argumenta que as sociedades elaboram mecanismos de seleção da sensibilidade em relação à violência. As tolerâncias ou indignações sobre determinadas formas de violência em que diversos grupos estão envolvidos estão engendradas nas diferenças de suas significações.

Certamente a violência homicida no Brasil seleciona grupos peculiares em termos de idade, gênero, cor/raça, renda, local de moradia e assim por diante, conforme Adorno (1994), Reis (2005), Lima (2009), Vargas (2010), Alves (2011, 2013), entre outros. O padrão da violência homicida encontrado por esses pesquisadores é um dos elementos da necropolítica estatal, mas esta coerência espacial que interconecta a segregação e a violência de forma sincrônica com as estruturas econômicas e sociais tem criado uma posição unívoca do fenômeno.

Nossa proposta é avançar na ideia de periferia urbana como componente de uma necropolítica espacial, tal como Alves (2013). Mas, diferentemente dele, superar a ideia de periferia urbana como espaço que expressa a segregação econômica e racial, compondo um resultado coerente com as estruturas de poder. Interpretamos aqui a periferia urbana como um espaço

8 Em Ponta Grossa, apenas 20,7\% da população é negra, considerando pretos e pardos, segundo o Censo 2010 (IBGE, 2011). 
que se faz e desfaz constantemente de relações específicas, a partir das interseções de idade, raça, gênero e atravessadas simultaneamente por múltiplas escalas. Ser homem, jovem, negro e morador de uma periferia pobre implica uma posição nas relações de poder que não pode ser visto como total e fixa, mas de encontros com "outros", o que reposiciona constantemente esses sujeitos nas relações de poder e constrói uma perspectiva política do espaço, tal como proposto por Massey (2008).

Esta ideia está inspirada por uma trajetória de pesquisa que se iniciou com a coleta de dados dos atos infracionais de adolescentes em conflito com a lei na Delegacia da Polícia Civil e Antitóxicos de Ponta Grossa a partir do ano 2005 até o presente. $\bigcirc$ envolvimento de adolescentes do sexo masculino nos atos infracionais era de quase $90 \%$ do universo considerado. Este percentual se mantém até os dias atuais, com pequeno aumento da participação feminina. As pesquisas de Chimin Junior (2009) e Rossi (2010) chegaram à conclusão de que os adolescentes do sexo masculino eram simultaneamente vítimas e autores de atos infracionais, constituindo códigos próprios de masculinidades que formam as precárias periferias urbanas. Esses códigos se fazem em processos de relações de poder com a moralidade social instituída, o que incita o substancialmente o aumento da vulnerabilidade dos adolescentes do sexo masculino e pobres aos atos infracionais e sua vinculação direta com o uso de substâncias químicas ilegais, notadamente o crack.

Posteriormente, os trabalhos de Gomes (2013) e Rocha (2013) analisaram o cotidiano dos adolescentes usuários de crack e seus agenciamentos para enfrentar as estruturas de poder que consideram suas vidas descartáveis. Esses pesquisadores apontam que aquilo que a nossa sociedade oferece como projeto de vida e condições materiais aos adolescentes do sexo masculino nas periferias pobres potencializa uma trajetória de vida violenta ou, a "vida louca" para utilizar as palavras do grupo pesquisado. Segundo o discurso dos adolescentes que fizeram parte das pesquisas, seu futuro está marcado pelo encontro dos dois "C" (Cadeia ou Cemitério). A trajetória da vida de jovens homens e o desfecho na cadeia foi explorado por Rossi (2017) e a vida permeada pela presença constante da morte (o Cemitério) foi explorada por Gomes (2013).

A trajetória de pesquisa que o Grupo de Estudos Territoriais empreendeu sobre jovens homens de periferias nos permite apontar para o fato de que a violência homicida é plurivocal, não havendo uma posição única dos jovens homens moradores de periferias. Eles são simultaneamente vítimas e autores da violência homicida, o que implica uma imaginação geográfica que desarticule a sincronia entre espaço e estruturas de poder, e torne o espaço paradoxal, descontínuo e aberto aos tensionamentos um caminho de compreensão para o fenômeno da espacialidade seletiva da morte que elege a periferia pobre como preferencial.

Os mecanismos que instituem a seletividade espacial da violência homicida fazem parte de uma estrutura organizacional de saber/poder que, por meios de dispositivos e micropoderes disciplinares perpetuados, reproduzidos ou rearranjados histórico-espacialmente, produzem o "outro" " "marginal" ou "delinquente" (Foucault, 1987). Os dispositivos se fazem de estratégias de relações de força que sustentam os saberes e de forma simultânea suporta os poderes, tecendo uma rede que envolve uma miríade de discursos, sejam eles legais, administrativos, científicos, morais, filosóficos ou arquitetônicos (Foucault, 2000b). 
Ao analisar os discursos jurídicos Foucault (2003) chama a atenção para a produção do saber/poder na definição do sujeito "criminoso" que, segundo ele, é aquele que danifica a sociedade e por isso mesmo se institui como um "inimigo social interno", cuja sociedade da qual ele faz parte deve sentenciá-lo, a fim de produzir a "normalidade" desejada. A criação das "condutas disciplinadas" e da produção da "normalidade" cria assim os limites para o reconhecimento do indivíduo "criminoso", aquele que a sociedade deve combater. Sua conduta totaliza o ser e, portanto, a pessoa deixa de ser alguém que cometeu um ato considerado crime, mas tornando-se um ser criminoso.

O poder disciplinador que se instaura na gestão da vida social, a biopolítica, cria aqueles que são desviantes da vida saudável e assim, para o bem da sociedade, podem morrer. Segundo Foucault (2000a, p. 304), ao estimular o crescimento da vida, a morte aparece não como imposição, mas como um benefício para a vida de todos e, sendo assim, "a morte do outro, a morte [...] do degenerado, é o que vai deixar a vida em geral mais sadia", criando-se assim a possibilidade de "mortes aceitáveis" e até "desejáveis" socialmente.

São os dispositivos que criam a ideia do "outro", aquele "anormal" que não se adequa aos ditames da normalidade e que, por isso, tornam-se passíveis de serem mortos "legitimamente" quando se constituem riscos àqueles considerados adaptados às normas estabelecidas. Assim, conforme Agamben (2010, p. 38), os direitos individuais específicos são suprimidos, justificando a funcionalidade de uma lógica social que se vê ameaçada, criando assim uma fronteira tênue em que a "violência traspassa em direito e o direito em violência". O mesmo agente político pode agredir a legalidade, mas quando a agride the autoconfere status de "necessidade" da eliminação daquele que é considerado "perigo social". As vidas desprovidas da garantia e expostas à morte são chamadas por Agamben (2010) de "vidas nuas". São vidas não qualificadas como vidas ou ainda aquelas vidas que se constituem em um tropeço para as vidas consideradas válidas socialmente.

As vidas nuas se instituem em um longo processo de invenção do "outro" em que as diferenças constituem hierarquizações sociais e espaciais, são limites que são constantemente alimentados pelos dispositivos de gestão da vida. Mbembe (2003) cunha o conceito de necropolítica para compreender a ideia de gestão da vida pela face do extermínio de parte da população. Segundo ele, a sociedade cria mecanismos que constitui seres humanos passíveis de serem descartados, pois são considerados supérfluos, são considerados sujeitos matáveis.

A necropolítica instituída no Brasil com relação às mortes de homens jovens negros e sua espacialização nas periferias pobres urbanas não deixa dúvida de que a sociedade brasileira constituiu os dispositivos capazes de produzir uma massa de cadáveres, considerada necessária para a manutenção da vida considerada qualificada. A insensibilidade de parte da sociedade pelo genocídio das periferias urbanas se constrói cotidianamente pela desumanização dos "outros" por meio dos discursos que permeiam instituições econômicas, políticas e culturais que são veiculadas pelos meios de comunicação.

A criação do distanciamento é necessária para que muitas mortes não sejam lamentadas socialmente. Žižek (2009, p. 45-46) afirma que "matar alguém à queima-roupa é para a maior parte dentre nós muito mais repulsivo do que apertar um botão que matará mil pessoas que não vemos". Dessa forma, mecanismos de distanciamento e aceitação são elaborados discursivamente para viabilizar e invisibilizar a violência predestinada a alguns grupos específicos. Esses mesmos 
mecanismos são capazes de canalizar o escoamento de um sangue "anônimo" e enclausurar o sofrimento do outro em locais específicos das cidades brasileiras, as periferias urbanas pobres.

$\bigcirc$ espaço das periferias urbanas pobres, nesse sentido, longe de ser coerente com a totalidade, uma área delimitada materialmente e o resultado de forças externas que nela se abatem, são lugares relacionais que se fazem da multiplicidade simultânea de escalas, pela qual o local e o global são mutuamente constitutivos, tornando impossível qualquer separação.

A vida cotidiana dos jovens homens envolvidos na violência homicida é realizada por inúmeras fontes que criam consequências e atingem incalculáveis escalas. $\bigcirc$ global não é algo abstrato, mas se materializa nas vidas dos jovens homens das periferias pobres. Para usar a proposição de Massey (2008), o lugar pensado de forma relacional é estabelecido na somatória de todas as conexões possíveis e essas conexões podem seguir ao redor do mundo. Logicamente o alcance da dispersão das conexões depende de cada grupo social, mas a imaginação geográfica das periferias urbanas pobres exige pensar a necropolítica pela conexão específica e simultânea de escalas, como lógica governamental liberal global do tráfico de drogas e sua financeirização, as estratégias nacionais, estaduais e locais do Estado e os agenciamentos de ações cotidianas dos sujeitos envolvidos na violência homicida. Esses feixes de relações que compõem as periferias pobres não têm uma configuração específica, mas deve ser vista em um processo constante de movimento e tensão.

A necropolítica espacial, portanto, não pode ser apenas concebida "de cima para baixo" como se as escalas fossem hierarquizadas. Os mecanismos que sustentam a necropolítica espacial são alimentados também por práticas elaboradas tanto entre seus pares identitários como na confrontação com o "outro". Žižek (2009) argumenta que a "enunciação" elaborada nos encontros entre "eu" e "outro", pode impulsionar práticas de violência. Essa violência latente pode ser pensada como um mecanismo de distanciamento produzido por meio de "fechamentos contingentes" cotidianos elaborados nos espaços de encontro entre diferentes. As necropolíticas espaciais, assim, não podem ser limitadas a análises zonais, mas para que sua eficiência se mantenha, elas acontecem em um agenciamento de atividades, como "ações sobre ações" (Foucault, 2006).

\section{Necropolítica espacial multiescalar e a mutualidade das trajetórias exis- tenciais no encontro homicida}

Esta seção se propõe a evidenciar que a violência homicida que ocorre na cidade de Ponta Grossa envolve elementos de diversas escalas e naturezas. Desde o aprofundamento do município nas redes do tráfico de drogas, a precariedade de bens e serviços urbanos, até dispositivos de construção de masculinidades próprias que suscitam o encontro conflituoso. Essas afirmações estão baseadas nos dados dos 86 inquéritos policiais e/ou processos judiciais definidos pelo artigo 121 do Código Penal Brasileiro - Decreto-lei no 2.848, de 7 de dezembro de 1940 (Brasil, 1940) -, enquadrado como um crime contra a vida, quando há uma morte de pessoa humana praticada por outra, podendo ser classificado como simples ou qualificado. Além desses, também foram considerados os homicídios tentados (artigo 121 c/c artigo 14, inciso II do Código Penal Brasileiro), ainda que não tenha tido a ocisão da vida da vítima, os casos, não podem ser investigado como "lesão corporal" - artigo 129, quando o dolo foi além 
de tentar ferir a integridade física, configurando-se em um assassinato frustrado. Esse adendo foi tomado pela pesquisa por entender que as dinâmicas de uma violência homicida podem acontecer, sem que haja uma morte. A proposta é compreender os assassinatos em seu arranjo espaço-temporal, se há o objetivo de matar a frustração torna-se um acaso da tentativa, são forças orgânicas fazendo parte do encontro conflituoso.

Entre os inquéritos investigados entre 2012 e 2015 no município de Ponta Grossa, foi levantado um total de 96 pessoas assassinadas, sendo que 86,5\% eram do sexo masculino. Esta estatística corresponde ao perfil nacional de vitimação masculina, que em 2010 era de 91,4\% (Waiselfisz, 2013). O município apresenta uma vitimação jovem, pois, considerando o mesmo universo de documentos, foi detectado que 37\% das vítimas tinham entre 15 e 25 anos, também coincidente com o padrão nacional, que é de 15 a 24 anos de idade9 (Waiselfisz, 2013). Outra característica do fenômeno é o aumento da vitimização de jovens homens negros em relação aos brancos. Analisando a série temporal entre 2001 e 2011, Waiselfisz (2014, p. 120) detectou a "queda no número de homicídios na população branca e o aumento do número de vítimas na população negra". Em 2001, morreram proporcionalmente 69,4\% mais negros que brancos e em 2011 esse índice subiu para 136,8\%. A vitimação negra fica ainda mais acentuada se interseccionada com a faixa jovem, pois para cada jovem branco que morre assassinado, morrem 2,5 jovens negros.

Em Ponta Grossa o perfil de cor da pele encontrado entre as vítimas foi de 54\% de brancos, $37 \%$ de pardos e $9 \%$ de pretos. Considerando que a população negra é a soma entre pardos e pretos, o município registrou $46 \%$ de vítimas negras. $\bigcirc$ Paraná tem a segunda menor população relativa negra do Brasil. Conforme o Censo de 2010 do Instituto Brasileiro de Geografia e Estatística (IBGE, 2011), apenas 28,2\% da população do estado é negra, se forem somadas as parcelas populacionais preta e parda. Portanto, a menor presença de negros nos números de assassinados se deve, de primeira mão, ao fato de a população do estado ser predominantemente branca. Em Ponta Grossa, há apenas 20,7\% de população negra em relação ao total. Ponta Grossa, portanto, é constituída de uma população mais branca que o segundo estado mais branco do país. Contudo, o município registrou 46\% de vítimas de homicídios sendo de pessoas negras. Portanto, mesmo em cidades com população majoritariamente branca, a mortandade de negros é significativa, o que reforça a tese de Nascimento (1978).

Assim como Alves $(2011,2013)$ afirmou haver uma organização espacial da governança da necropolítica em São Paulo, podemos utilizar um mesmo argumento para compreender a distribuição das mortes em Ponta Grossa. Mas essa organização espacial da governança da necropolítica, se dá na constituição das periferias em conexões específicas, reunindo elementos de várias escalas espaciais, desde o envolvimento com as redes mundiais de tráfico de drogas, as ações segregacionistas promovidas pelo Estado em suas várias instâncias, bem como o cotidiano marcado por conflitos pessoais. Ponta Grossa, apesar de reduzida população negra, como já explicitado anteriormente, apresenta a interseção entre renda e raça, como pode ser visto na Figura 1.

9 A "vitimização" de jovens por homicídio é estabelecida, segundo Waiselfisz (2012), pela comparação entre a taxa de homicídio da população de 15 a 24 anos de idade e as demais taxas correspondentes a outros grupos etários. Levando em conta esses dados, no ano 2000, os homicídios na faixa jovem foram 150,2\% superiores aos no restante da população, e, segundo Waiselfisz (2012), em 2007, essa concentração foi ainda maior. 
Figura 1 - Local de moradia da população pobre e negra em Ponta Grossa, Paraná*
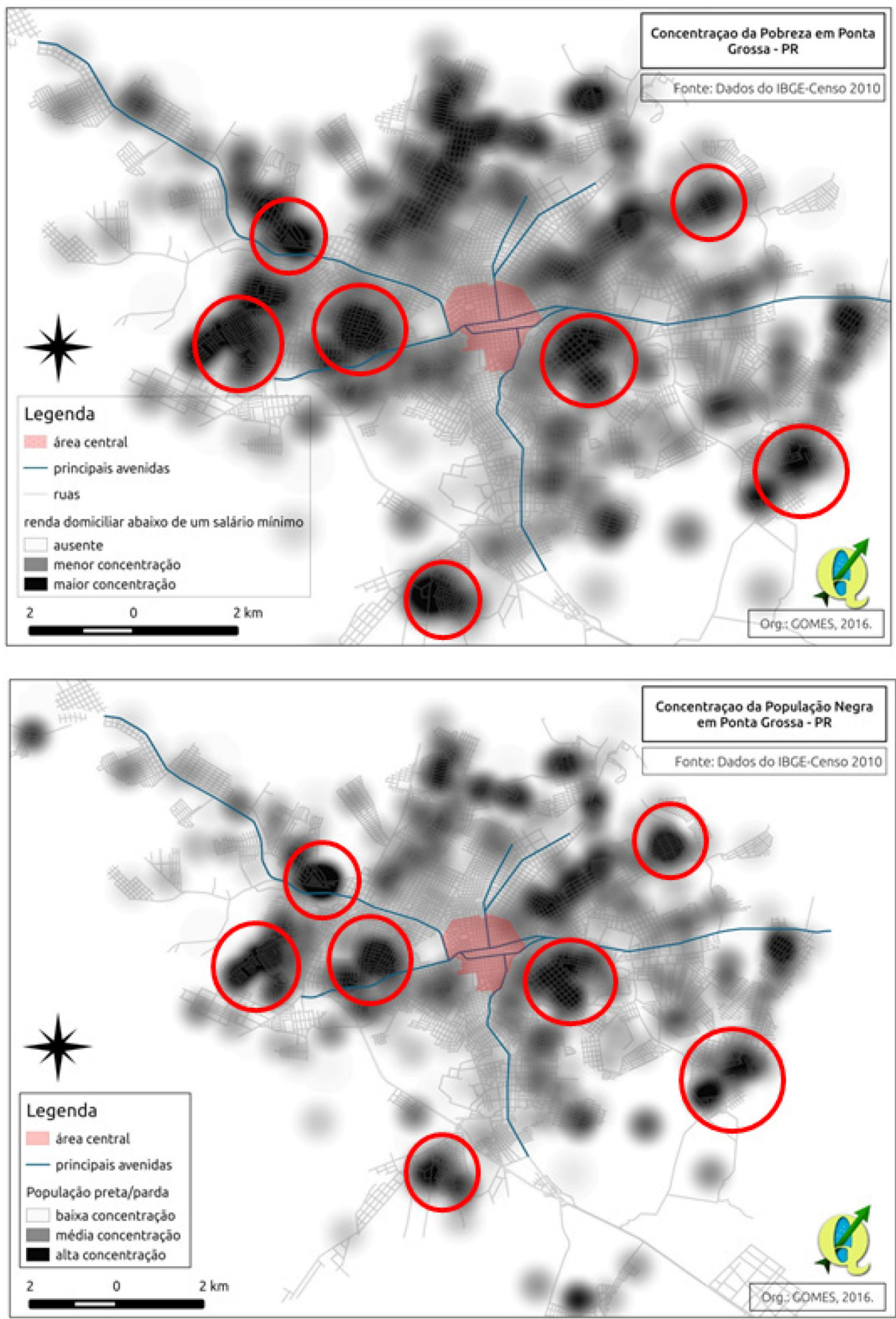

fonte: dados do Censo 2010 - IBGE (2011).

* População negra considerou a soma de pretos e pardos. 
A Figura 1 permite afirmar que nem toda pobreza da cidade é negra, mas quase a totalidade da população negra é residente em áreas pobres. Conforme o Mapa da pobreza e desigualdade dos municípios brasileiros produzido pelo IBGE (2003), Ponta Grossa tem um elevado índice de pobreza, atingindo 41,62\% da população. Esse índice é superior aos encontrados para outras cidades médias como Londrina (36,49\%), Maringá (33,85\%) e a capital Curitiba (31,71\%). Conforme Nascimento e Matias (2011), entre 1960 e 2006 a população que reside em favelas passou de 0,8\% para 17,2\% distribuídos em 136 pontos de ocupação. Elementos que contribuem para compreensão da distribuição espacial da desigualdade de renda.

Pensar a violência homicida na cidade é pensar sua dinâmica de ocupação, ordenamento e disposição social no espaço-tempo urbano. A geografia do fenômeno da morte violenta está nas subjetividades que a compõem por meio de uma espacialidade que possibilita os encontros. Portanto, além de conferir-lhe as localizações dos envolvidos e do local do crime, estes precisam ser pensados como um agenciamento de complexas inter-relações que arranjam os espaços de vivência e sobrevivência.

$\bigcirc$ perfil mais vitimado pela violência homicida em Ponta Grossa é de homens entre 15 e 25 anos, baixa escolaridade, solteiros e com empregos informais de baixa qualificação e baixos rendimentos. $\bigcirc$ local de moradia das vítimas registrado nos documentos jurídicos aponta para áreas precárias de serviços e infraestrutura, sendo distantes do centro, e quando mais próximas, são áreas de ocupação irregular em áreas de risco, próximas aos fundos de vale dos rios urbanos. Interessante constatar que não há registro de vítimas na área central e nas áreas de concentração da população de maior rendimento.

Em geral, os relatórios estatísticos e a grande parte das pesquisas sobre violência homicida posicionam os autores dos homicídios em segundo plano. Contudo, compreender a violência homicida significa também considerar sujeitos autores e suas dinâmicas existenciais. ${ }^{10}$ A autoria de um homicídio tem uma trama performativa que envolve agenciamentos a serem considerados. Portanto, assim como as vítimas, o levantamento sistematizado do campo investigativo também considerou as informações sobre os autores dos homicídios.

Dos 86 inquéritos foram levantados 105 autores de homicídios. Destes, 95,2\% são do sexo masculino, o que representa um percentual maior daquele detectado entre as vítimas que é de $86,5 \%$. 55,5\% dos autores são brancos, 41,7\% pardos e 2,8\% pretos. Os autores são majoritariamente jovens, com baixa escolaridade (Ensino Fundamental incompleto), são moradores de áreas pobres e têm ocupações de baixa qualificação e rendimento como serventes de pedreiro, pintores ou desempregados. São majoritariamente solteiros.

A proximidade do perfil entre autor e vítima abre uma possibilidade de reflexões que contestam as construções discursivas midiáticas hegemônicas, assim como a premissa jurídica, de que a vítima e autor estão posicionados em espacialidades oposicionais, como pode ser visto na Figura 2.

10 Talvez a dificuldade de discutir os autores se deva à dificuldade de obter dados, devido à baixa taxa de resolução dos crimes desse perfil. A própria metodologia deste estudo teve que considerar o perfil de pessoas indiciadas e pessoas iminentemente suspeitas pelo conjunto de informações obtidas pela Polícia Civil. Os dados limitados são a expressão da natureza de onde são produzidos, pelas investigações policiais que atendem a uma série de estatutos burocráticos e condutas de trabalho. 
Figura 2 - Local de moradia da vítima e autor de homicídios entre 2012 e 2015 em Ponta Grossa-PR

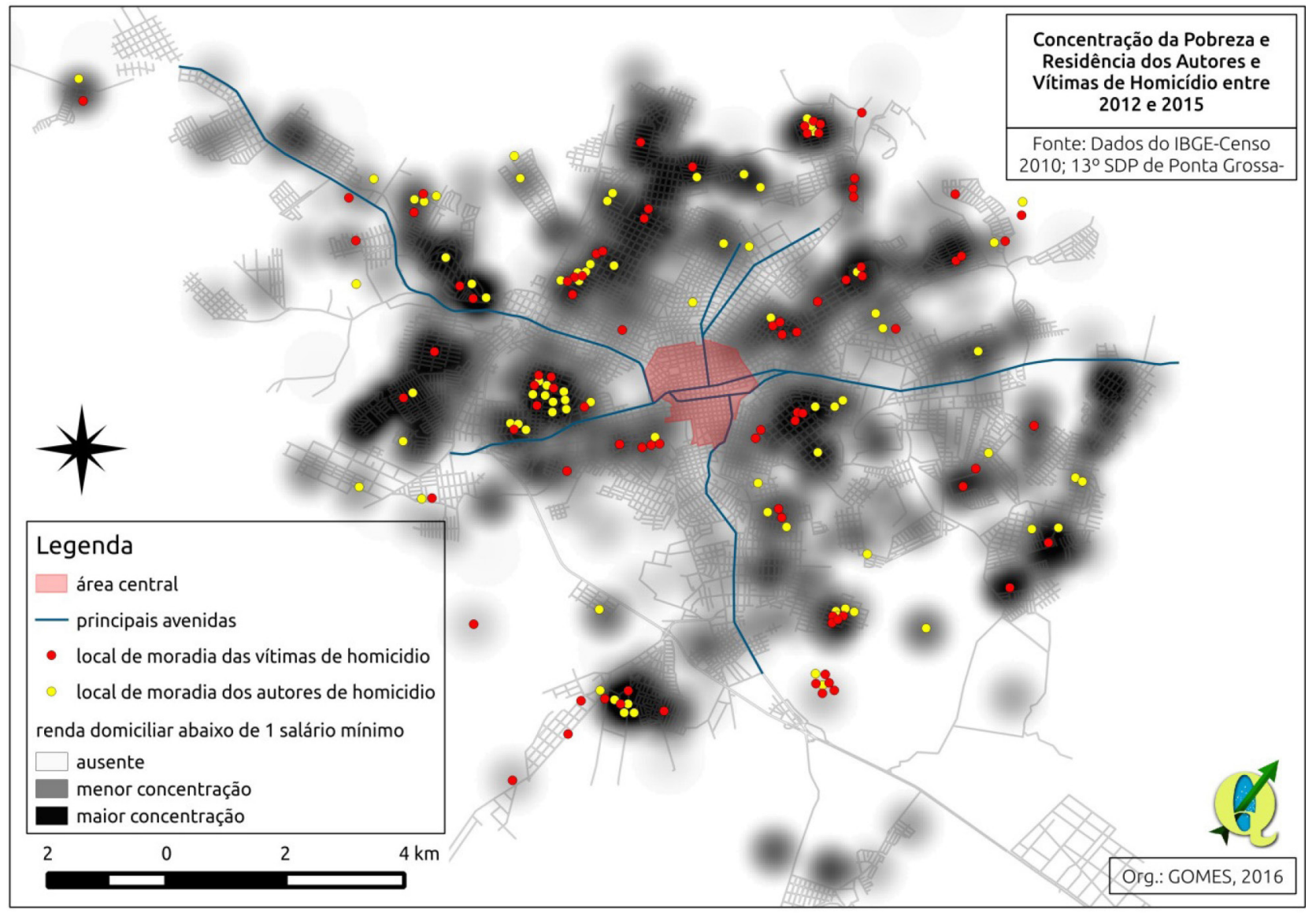

fonte: Dados do Censo 2010 (IBGE, 2011).

$\bigcirc$ perfil coincidente entre vítimas e autores de violência homicida, inclusive posicionados em periferias pobres permite a afirmação de que não há oposição entre eles. $\bigcirc$ que ocorre são encontros violentos que são propiciados em uma espacialidade em que se conectam os elementos multiescalares das necropolíticas.

É preciso superar a ideia da "predisposição" individual das pessoas envolvidas na violência homicida, mas pensar que ela se dá em uma dinâmica histórico-espacial complexa. Espacialidades tensionadas por conflitos gerados por desavenças, ameaças, dívidas materiais e morais, acordos desfeitos e práticas que, pela falta de mecanismos apropriados de resolução de conflitos, precária cidadania, acabam tendo desfechos solucionados de forma individual. Gomes (2013), ao analisar a produção discursiva de construção das masculinidades de adolescentes vítimas de homicídios argumenta que há uma performatividade engendrada na própria gestão de "tornar-se" homem frente aos seus pares identitários.

Nos documentos analisados em que constam depoimentos, declarações, e as cenas do crime, é possível afirmar algumas características do encontro litigioso. Os crimes ocorrem em sua maioria no período da noite e madrugada (73,2\%), durante os finais de semana. $\bigcirc$ meio mais utilizado para matar é arma de fogo (52,3\%), seguido de arma branca (20,9\%) e depois agressão $(17,4 \%)$, o restante é disperso nas mais infinitas formas de matar alguém, fogo, trilho de trem, degolado etc. A localização dos homicídios pode ser vista na Figura 3. 
Figura 3 - Local registrado das ocorrências de homicídios entre 2012 e 2015 em Ponta Grossa-PR*

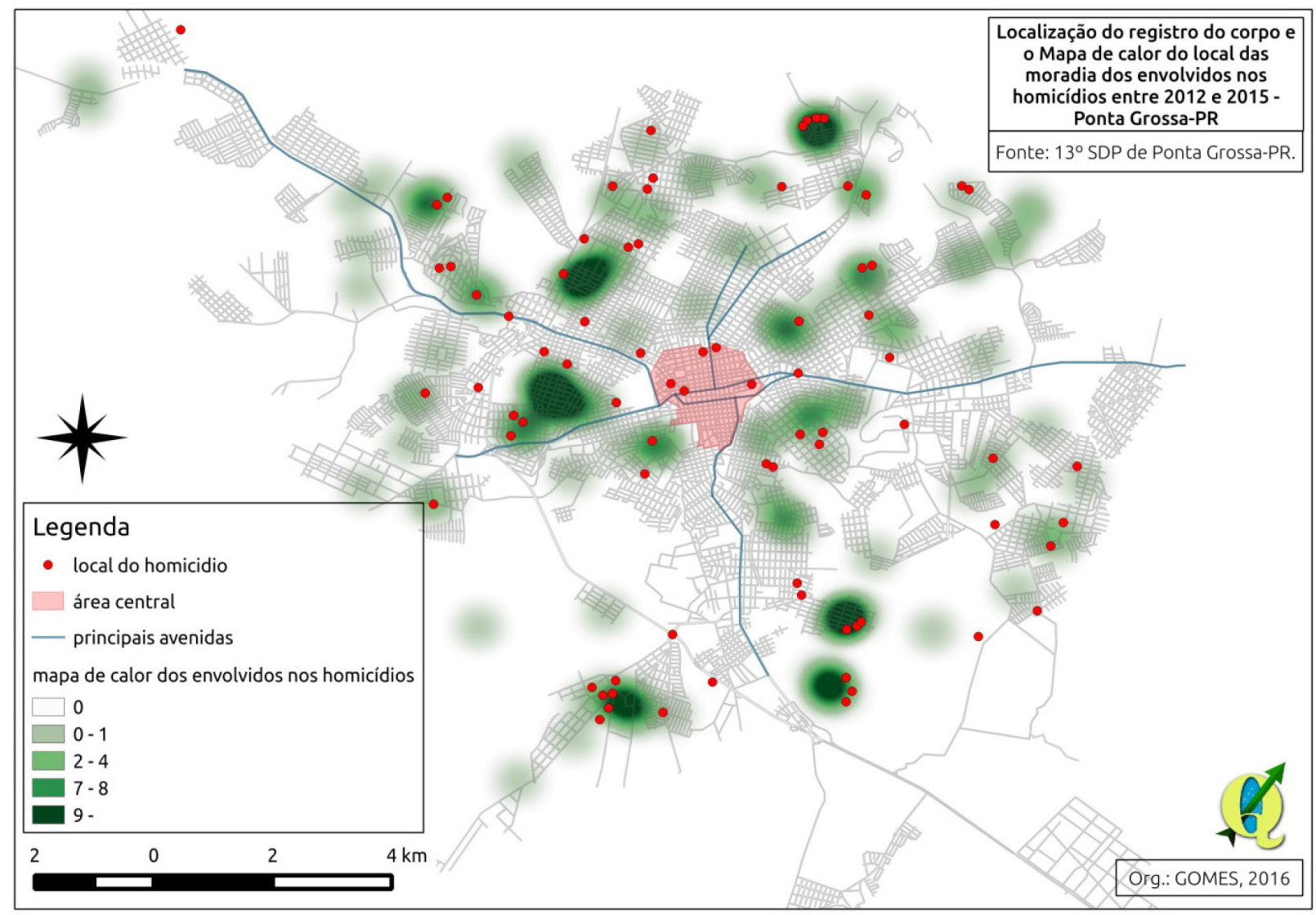

fonte: Dados do Censo 2010 (IBGE, 2011).

* População negra considerou a soma de pretos e pardos.

Na linguagem diagramática do mapa podemos ressaltar três características a serem problematizadas: (i) há uma concentração dos locais de homicídio ou de registro do corpo nos locais de residências dos autores e das vítimas; (ii) em pontos específicos há uma concentração periférica do local do homicídio em relação às áreas de moradia dos envolvidos; (iii) surgem registros de homicídios na área central e nas principais vias da cidade.

A primeira característica aponta para espacialidades de conflito, restando saber, mediante sistematização, se a lógica entre quem mata e quem morre é "intravila". A segunda característica expressa uma elemento recorrente nos casos analisados, que é o conflito ser efetuado nas extremidades das vilas periféricas configurando pontos de encontros de uso e venda de drogas ilícitas ou devido a busca por amenidades condenatórias de possíveis flagrantes, se aproximando dessa forma de áreas isoladas, de matagais, pequenos bosques, e matas em torno de rios. Já os homicídios que ocorrem em áreas centrais, ainda que os envolvidos sejam procedentes de áreas da periferia, pode-se apontar para o fato de que a maioria deles ocorreu em horário noturno. Chimin Junior (2009) e Rossi (2010) encontraram a mesma dinâmica conflitiva na área central e concluíram que em uma cidade de porte médio, homocêntrica como é o caso de Ponta Grossa, a oferta de bens e diversão está mais concentrada na área central, possibilitando o encontro conflitivo. 
As narrativas sobre o crime presente nas declarações, depoimentos e interrogatórios apontam que o eixo mais frequente da dinâmica dos assassinatos está tramado com a territorialidade do tráfico de drogas e a precariedade das áreas pobres. Esse eixo mais frequente é composto de jovens e adolescentes do sexo masculino, usuários e traficantes de drogas, envolvidos em mortes efetuadas em carreiros, barracos, becos, em sua maioria por meio de arma de fogo.

Outra forma de narrativa encontrada está relacionada com homens jovens pobres, sob o efeito do álcool, tramados numa rede de desavenças, estórias entrelaçadas, num emaranhado de confrontos e vinganças vinculadas a mulheres, familiares e rede de amigos, ou até mesmos grupos urbanos identificados com uma vila específica.

A análise dos dados evidencia que a governança espacial da necropolítica nas periferias pobres urbanas brasileiras têm elementos que perpassam a lógica de produção do espaço urbano das grandes e médias cidades. Contudo, é preciso compreender as periferias de forma complexa, sem que ela apareça como um reflexo das estruturas de opressão, mas como encontros de feixes de relações de poder que se interceptam de forma específica naquele espaço.

\section{Considerações finais}

Este artigo construiu uma compreensão da violência homicida como constituidora das periferias pobres vivenciadas por jovens homens, contribuindo para a análise geográfica das necropolíticas. As escalas do fenômeno são coextensivas e imbricadas, o que traz com maior clareza as estratégias de produção de morte e gestão dos vivos. A violência homicida acontece por meio de espacialidades permissivas, se considerado que as práticas que as compõem se caracterizam como a própria suspensão de regulações que amparam condições básicas de cidadania. Assim, é preciso ressaltar que, ainda que exista uma espacialidade que territorializa e confina a violência, a permissão é discursivamente incorporada em formas de vida específicas e transcende um confinamento zonal. $\bigcirc$ êxito na perpetuação dessas espacialidades permissivas está na sua interescalaridade.

\section{Referências}

ADORNO, S. Crime, justiça penal e desigualdade jurídica: as mortes que se contam no tribunal do júri. Revista USP, Dossiê Judiciário, São Paulo, n. 21, p. 133-151, 1994.

AGAMBEN, G. Homo Sacer: o poder soberano e a vida nua I. Belo Horizonte: Ed. UFMG, 2010.

ALVES, J. A. From Necropolis to blackpolis: necropolitical governance and black spatial praxis in São Paulo, Brazil. Antipode, Medford, v. 46, n. 2, p. 323-339, 2013.

Topografias da violência: necropoder e governamentalidade espacial em São Paulo. Revista do Departamento de Geografia - USP, São Paulo, v. 22, p. 108-134, 2011.

ANISTIA INTERNACIONAL. Você matou meu filho: homicídio cometido pela polícia militar na cidade do Rio de Janeiro. Rio de Janeiro: Anistia Internacional, 2015. 
BRASIL. Decreto-lei no 2.848, de 7 de dezembro de 1940. Código Penal. Diário Oficial da União, Rio de Janeiro, 31 dez. 1940.

CHIMIN JUNIOR, A. B. O espaço como componente de vulnerabilidade aos atos infracionais desenvolvidos por adolescentes do sexo masculino em conflito com a lei em Ponta Grossa - Paraná. Dissertação (Mestrado em Gestão do Território) - Universidade Estadual de Ponta Grossa, Ponta Grossa, 2009.

FÓRUM BRASILEIRO DE SEGURANÇA PÚBLICA. Anuário Brasileiro de Segurança Pública 2015. Fórum Brasileiro de Segurança Pública, 2015. Ano 9.

FOUCAULT, M. História da sexualidade I: a vontade de saber. Rio de Janeiro: Graal, 2006.

A verdade e as formas jurídicas. Rio de Janeiro: Nau, 2003.

Em defesa da sociedade: curso no Collège de France (1975-1976). São Paulo: Martins Fontes, 2000a.

Microfísica do poder. 15. ed. Rio de Janeiro: Graal, 2000b.

Vigiar e punir: nascimento da prisão. Tradução de Raquel Ramalhete. Petrópolis: Vozes, 1987.

GOMES, F. B. "Cenas embaçadas": a relação entre as espacialidades vivenciadas por jovens do sexo masculino e a morte por homicídio na cidade de Ponta Grossa, Paraná. Dissertação (Mestrado em Gestão do Território) - Universidade Estadual de Ponta Grossa, Ponta Grossa, 2013.

IBGE. Instituto Brasileiro de Geografia e Estatística. Censo Demográfico 2010: características da população e dos domicílios. Rio de Janeiro: IBGE, 2011. Disponível em: https:// biblioteca.ibge.gov.br/visualizacao/periodicos/93/cd_2010_caracteristicas_populacao_ domicilios.pdf. Acesso em: 8 fev. 2018.

Mapa da pobreza e desigualdade. 2003. Disponível em: https://cidades.ibge. gov.br/brasil/pr/ponta-grossa/pesquisa/36/30246. Acesso em: 8 fev. 2018.

INGRAM, M. C.; COSTA, M. M. da. Targeting violence reduction in Brazil: policy implications from a spatial analysis of homicide. Policy Brief, 2014. (Latin America Initiative, Foreign Policy at Brookings).

IPEA. Instituto de Pesquisa Econômica Aplicada. Atlas da Violência. Nota Técnica, n. 17. Brasilia, DF: Fórum Brasileiro de Segurança Pública, 2016.

LEFEBVRE, H. The Production of Space. Oxford: Basil Blackwell, 1991.

LIMA, C. B. de. Jovens em conflito com a lei: liberdade assistida e vidas interrompidas. Londrina: EDUEL, 2009.

MASSEY, D. Pelo espaço: uma nova política da espacialidade. Rio de Janeiro: Bertrand Brasil, 2008.

MBEMBE, J.-A. Necropolítica seguido de Sobre el gobierno privado indirecto. Trad. e Ed. Elisabeth Falomir Archambault. Numancia, ES: Melusina, 2011. 
Necropolitics. Public Culture, Durham, v. 15, n. 1, p. 11-40, 2003.

NASCIMENTO, A. O genocídio do negro brasileiro: processo de um racismo mascarado. Rio de Janeiro: Paz e Terra, 1978.

NASCIMENTO, E.; MATIAS, L. Expansão urbana e desigualdade socioespacial: uma análise da cidade de Ponta Grossa (PR). RA' E GA, v. 23, p. 65-97, 2011.

\section{PARANÁ. Relatório Estatístico Criminal da Secretaria da Segurança Pública do} estado do Paraná - 2010 a 2015. Secretaria da Segurança Pública/Administração Penitenciária, [s.d.]. Disponível em: http://www.seguranca.pr.gov.br/modules/conteudo/conteudo.php?conteudo=38. Acesso em: 8 fev. 2018.

REIS, V. Atucaiados pelo Estado: as políticas de Segurança Pública implementadas nos bairros populares de Salvador e suas representações, 1991-2001. Dissertação (Mestrado em Ciências Sociais) - Universidade Federal da Bahia, Salvador, 2005.

ROCHA, H. L. Espaço espiado: o uso de crack como um elemento das espacialidades vivenciadas por adolescentes do sexo masculino em Ponta Grossa-PR. Dissertação (Mestrado em Gestão do Território) - Universidade Estadual de Ponta Grossa, Ponta Grossa, 2013.

ROSSI, R. Espacialidade carcerária e a instituição de masculinidades entre homens jovens egressos em Ponta Grossa-PR. Tese (Doutorado em Geografia) Universidade Estadual de Ponta Grossa, Ponta Grossa, 2017.

"Malucos da quebrada": territórios urbanos na complexidade espacial cotidiana dos adolescentes homens em conflito com a lei em Ponta Grossa - Paraná. Dissertação (Mestrado em Gestão do Território) - Universidade Estadual de Ponta Grossa, Ponta Grossa, 2010.

SANTOS, M. O espaço do cidadão. 7. ed. São Paulo: Edusp, 2007.

THRIFT, N. Immaculate Warfare? The Spatial Politics of Extreme Violence. In: GREGORY, D.; PRED, A. Violent geographies: fear, terror, and political violence. New York: Routledge Taylor E Francis Group, 2006. p. 273-294.

VARGAS, J. C. A diáspora negra como genocídio: Brasil, Estados Unidos ou uma geografia supranacional da morte e suas alternativas. Revista da Associação Brasileira de Pesquisadores(as) Negros(as) - ABPN, Goiânia, v. 1, n. 2, p. 31-65, 2010.

WAISELFISZ, J. J. Os jovens do Brasil: Mapa da Violência 2014. São Paulo: Juventude Viva/Secretaria Nacional de Juventude, 2014.

Mapa da violência: homicídios e juventude no Brasil. São Paulo: Instituto Sangari, 2013.

Mapa da violência: os novos padrões da violência homicida no Brasil. São Paulo: Instituto Sangari, 2012.

Mapa da violência: os jovens do Brasil. São Paulo: Ministério da Justiça, 2011.

ŽIŽEK, S. Violência - seis notas à margem. Lisboa: Relógio D’ Água, 2009. 